John Carroll University

Carroll Collected

Philosophy

3-2004

\title{
The Goals and Merits of a Business Ethics Competency Exam
}

Earl W. Spurgin

John Carroll University, espurgin@jcu.edu

Follow this and additional works at: http://collected.jcu.edu/phil-facpub

Part of the Ethics and Political Philosophy Commons

\section{Recommended Citation}

Spurgin, Earl W., "The Goals and Merits of a Business Ethics Competency Exam" (2004). Philosophy. 5.

http:// collected.jcu.edu/phil-facpub/5

This Article is brought to you for free and open access by Carroll Collected. It has been accepted for inclusion in Philosophy by an authorized administrator of Carroll Collected. For more information, please contact connell@jcu.edu. 


\section{The Goals and Merits of a Business Ethics Competency Exam By Earl W. Spurgin}

My university recently established a business ethics competency exam for graduate business students that is administered twice yearly. I am one of two people who developed and jointly administer the exam. ${ }^{1}$ I suspect that some readers will find the idea of such an exam interesting, while others will be skeptical of its merits. Through this paper, I hope to begin a discussion among business ethicists about both the merits of a competency exam and what the format of such an exam should be. I will attempt to do this by explaining the reasons why my institution adopted a competency exam, the goals and purposes of the exam, the format of the exam, and why I believe the exam has merit. I will close by suggesting some questions related to the exam that I hope business ethicists will pursue.

\section{Reasons for the exam}

For some time, the school of business at my university has required that its graduate students take a management course titled "Ethics and Business Environmental Issues." The course description reads, "A consideration of the social, political, legal, and ethical constraints on business policies and managerial decision making" (John Carroll University, 2002-2004, p. 55). Ever since a business ethics course offered by the philosophy department was added to the business core requirements for undergraduates, many in the school of business have been concerned that the graduate course is repetitive for those students who come through their undergraduate programs.

In addition to that concern, they faced pressure to develop M.B.A. and M.S. in Accountancy programs that can be completed in one year. Since 150 credit hours are now required to sit for the uniform CPA exam, they wanted to provide graduate programs for those students who wish to obtain graduate business degrees as they complete the required hours.

Moreover, other institutions with which they must compete for students offer one-year graduate business degrees. When considering how they could streamline their graduate degrees to produce one-year programs, members of the business faculty sought to eliminate any repetition. Since many already had such concerns about the Ethics and Business Environmental Issues course, it became an obvious course to evaluate.

Members of the business faculty, however, did not want to cut the course from their programs for two reasons. First, because many of their graduate students obtain undergraduate degrees at other institutions, they were not sure that the course would be repetitive for those students.

Some institutions do not require their undergraduate business majors to take business ethics at all, and, even if they do, business faculty members could not be confident of the quality and content of those courses. Lacking that information, they could not be sure that the graduate course in fact would be repetitive for many students. Second, as faculty members at a Jesuit institution, they are committed to ethics and did not want to run the risk of some students missing what they believe to be one of the most important components of their educations. That risk comes from both those students who obtain their undergraduate degrees at other institutions and those students from their own institution who, because they do not devote enough effort to the course, do not come away from the undergraduate business ethics course with all they need. 
This is where I entered the picture. I am the professor in the philosophy department whose main teaching responsibility is the undergraduate business ethics course and whose main research area is business ethics. Members of the business faculty asked me to consider whether a business ethics competency exam could be constructed. If such an exam could be constructed, they could continue to require the graduate course but waive the requirement for those students who, through their performance on the exam, could prove that the course truly would be repetitive for them. When considering this possibility, they wanted me to bear in mind the two reasons why they did not want to cut the graduate course from their programs. In particular, they wanted assurance that a competency exam truly could test whether a particular student is competent in business ethics. Not only did they want to maintain the emphasis of ethics that is demanded by a Jesuit institution, they did not want to give even the appearance of deemphasizing ethics. Although the many recent corporate scandals had not yet surfaced when they came to me with this idea, the current climate adds further legitimacy to their concerns.

I was pleased that the business faculty members did not wish to de-emphasize ethics and that they sought advice outside their own school regarding the merits of instituting a competency exam. It was apparent to me that they continued to take ethics seriously and truly sought to eliminate repetition for qualified students. After examining the content of the graduate course alongside the content of my own course, I determined that such an exam could be constructed. A properly constructed exam would identify those students for whom the graduate course truly would be repetitive, as well as those students who need the graduate course. One of the business professors who teaches the graduate course and I forged a partnership to develop and administer the exam.

\section{The exam}

The main goal of the exam is to determine whether students are competent in business ethics. This means that we must determine whether students possess both the basic knowledge of theories, concepts, and issues that a person competent in business ethics should possess and the ability to reason ethically about a wide variety of business ethics issues. To determine whether students possess the required knowledge and ability, we developed an exam that requires students to demonstrate that they can:

1) "speak the language" of business ethics,

2) identify business ethics issues,

3) apply theories and concepts to issues,

4) identify connections among theories and concepts as they relate to different issues, and

5) construct and critically evaluate arguments for various positions on business ethics issues.

We arrived at these abilities by considering the goals of both the undergraduate business ethics course and the graduate Ethics and Business Environmental Issues course. Although there are some differences in the goals of the two courses, we were able to settle on a set of abilities that we believe one who is competent in business ethics should possess. These abilities are not merely abilities that we expect to find in successful undergraduates, nor does the exam measure them on undergraduate standards. While I teach the undergraduate course but not the graduate course, my partner teaches the graduate course but not the undergraduate course. His input on both the design and the grading of the exam is based solely on what he believes graduate 
students who are competent in business ethics should be able to accomplish. The above set of abilities, then, are those we expect MBA students who are competent in business ethics to possess.

To arrive at these abilities, we also accounted for the differing approaches to business ethics by philosophers and non-philosophers. I am a philosopher but my partner is a professor in the Department of Management, Marketing, and Logistics. We were both involved in the development of the exam. While I brought a philosopher's emphasis on argumentation and critical analysis to that development, my partner brought a management professor's emphasis on human resource procedures. Moreover, since we both grade the exams, we bring those emphases to the scoring. The result is that the exam gives appropriate attention to the approaches of philosophers and non-philosophers alike.

We administer the exam to students who are both eligible and interested early in the fall semester and late in the spring semester of each academic year. To be eligible, students must have completed an undergraduate business ethics course with a grade of $\mathrm{C}$ or above. The exam is in two parts taken on separate days. The first contains multiple-choice questions and the second is a case analysis. Weeks before the exam dates, interested students are given an information sheet that describes what they must accomplish to be successful on the exam. It begins with the following:

Business students should have a basic understanding of many important ethical theories, concepts, and issues. You will be asked to demonstrate your understanding through an examination comprising two parts. The first part consists of objective questions. The second part is a case analysis. To be successful on this exam, you should be able to accomplish the following objectives:

1) Identify business ethics issues.

2) Explain, compare, and contrast theories and concepts related to business ethics issues.

3) Raise and evaluate possible objections to the theories and concepts.

4) Construct arguments for and against the various positions related to the ethical issues.

5) Use the theories and concepts in the construction of those arguments.

6) Apply the arguments, theories, and concepts in case analyses.

The information sheet also contains four lists of theories, concepts, and issues about which students should be knowledgeable. The first is a list of basic ethical theories that we believe one must know in order to demonstrate competency in any area of ethics. They are: relativist, egoist, utilitarian, Kantian, Rawlsian, and libertarian theories.

The second is a list of basic ethical and philosophical concepts that, again, we believe one must know in order to demonstrate competency in any area of ethics. They are: argument, premise, conclusion, moral agent, duty, right, supererogatory act, autonomy, paternalism, equality, justice, just deserts, due process, human rights, property, privacy, discrimination, lying, deception, and harassment.

Next is a list of concepts that are more specific to business ethics. These are not necessarily concepts we believe one must know in order to demonstrate competency in any area of ethics, but, rather, concepts one must know to demonstrate competency in business ethics specifically. They are: special ethics for business, game analogy argument, corporation, fiduciary, fiduciary interests, stakeholder, stakeholder interests, social responsibility, 
entrepreneurial risks, invisible hand, social contract between business and society, employment at will, employee bill of rights, bribes, gifts, insider, and inside information.

The last is a list of some important business ethics issues. Although it would be practically impossible to construct an exhaustive list of business ethics issues, we wanted a list of several issues that both are important and raise the sorts of ethical questions that allow students to demonstrate their competence, or their lack thereof, in reasoning through issues in business ethics. The list contains: the corporation as moral agent, marketing practices, product safety, employment at will, employee rights, employee privacy, occupational safety, employment discrimination, comparable worth, affirmative action, sexual harassment, whistleblowing, bribery and kickbacks, insider trading, business in foreign countries, and the environmental impact of business.

The information sheet closes with a list of suggested readings. Among them are books on basic philosophical and ethical concepts, business ethics texts, business ethics casebooks, and business ethics anthologies. The list is intended to provide students with resource material so they can prepare for the exam. Some students might simply need reminders about some theories, concepts, or issues, some might need to do serious work to fill major holes in their business ethics backgrounds, and some might need something in between. In any case, the list of suggested readings provides students with resources than can help in their preparation.

\section{The multiple-choice section}

Students have two hours to complete the multiple-choice section of the exam. On the day of the exam, we give the students exam sheets containing fifty-five multiple-choice questions of which each student must answer fifty. We do this so that each student can omit any questions that the student believes are unclear. In this way, we avoid the potentially endless complaints that some question or other was poorly written or was ambiguous. If a particular student believes this is the case of certain questions while taking the exam, then that student can omit them. If the student answers a question, then the student has little basis for complaints regarding that question later.

The goal of this part of the exam is to determine whether students possess the basic knowledge of theories, concepts, and issues that a person competent in business ethics should possess. The questions in this part are designed to allow students to demonstrate, or fail to demonstrate, that they possess the first four of the five abilities identified at the beginning of this section.

We use several types of multiple-choice questions to determine if students possess those abilities. In most cases, students must choose from among four or five possible answers. Some questions are relatively simple questions of this form: The $X$ theory of responsibility for product safety is . . . Others ask questions about the ideas of certain prominent figures in business ethics such as the following: According to Milton Friedman's view of corporate social responsibility, businesspersons who ... or According to Lynn Sharp Paine, marketing products to children .... . Through these sorts of questions, students demonstrate whether they can "speak the language" of business ethics. They cannot do well on these questions unless they are familiar with the terminology business ethicists employ. They must know the common terms of business ethics such as "stakeholder," "game analogy," "social responsibilities," "caveat emptor," "employment at will," "fiduciary duties," and many others. 
Although those types of questions are useful in helping to achieve the goal of the multiple choice section of the exam, they cannot achieve it by themselves. We want to determine if students understand the theories, concepts, and issues. To do that, we must make sure that they cannot simply memorize their way to a good score. For this reason, we have questions that require students to apply theories and concepts. Such questions often have the following forms: Concept $X$ is often used as a basis for an argument that . . or One who argues X most likely holds .... Such questions move away from testing for familiarity with terms to testing for the ability to work through ideas.

Even this move, however, is not enough to accomplish our goal. We want to ask questions that require more sophisticated reasoning than such questions allow. Consequently, perhaps the most useful type of question we employ is the scenario type. Several times throughout the exam, students must read a short scenario and then answer several questions about that scenario. This forces students not only to demonstrate the ability to apply theories and concepts, but, also, to identify business ethics issues and to discover connections among theories and concepts related to those issues. When these questions are combined with the types of questions described earlier, students must demonstrate a true competence in order to perform well. Simple memorization will not suffice.

The following is typical of the sorts of scenarios we use in the exam:

\begin{abstract}
Jane owns a car dealership. She has 25 employees who work in the office. These employees do most of their work on computers. Jane allows them to use e-mail and the Internet during their lunch breaks and before and after work. Although her employees do not know this, Jane monitors the websites her employees visit and reads their e-mails. She reasons that the computers are her property so she has the right to monitor what is done on them. Recently, Jane read an e-mail written by Jerry after working hours. In this message, he told a friend what he thinks about his boss. He wrote, "She is the dumbest person I know. If she hadn't divorced her husband and stole his dealership in the divorce settlement, she'd be hooking for a living." Jane was taken aback. Jerry was her most efficient employee, and he had never been anything but kind to her. Jane fired him the next day.
\end{abstract}

Such a scenario allows for the construction of a wide variety of good questions. They can range from the very basic, such as Which of the following issues is raised by this scenario? or According to George Brenkert's theory of employee privacy, Jane acted . . ., to those that require considerably more reasoning, such as Which of the following is the least plausible basis for an argument that it was ethical for Jane to fire Jerry? or A libertarian would most likely conclude that....

Through the variety of questions we employ in the multiple-choice section of the exam, we are able to achieve our goal. Students demonstrate, or fail to demonstrate, that they can "speak the language" of business ethics, identify business ethics issues, apply theories and concepts to issues, and identify connections among theories and concepts as they relate to different issues.

\title{
The case analysis
}

The main goal of the case analysis is to determine whether students possess the abilities to construct and critically evaluate arguments for various positions on business ethics issues. 
Although this is the last of the five abilities identified at the beginning of this section, in many ways it is the most important. Unfortunately, multiple-choice questions are not as effective in determining whether students possess it as they are in determining whether students possess the other four. A case analysis, on the other hand, is extremely effective.

We give students the case twenty-four hours before they must write their analyses. Along with the case, they receive a reminder both of the objectives they must be able to achieve and that they are not permitted to work together. They are also informed that, to sit for the case analysis, they must be able to sign truthfully a testament that reads as follows: "I have independently researched and studied the case. I have not discussed it with anyone else, nor have I used information collected by anyone else."

On the day of the exam, students have two hours to write their analyses. They are not permitted to use any notes or other materials. We provide a clean copy of the case, the testament, and the following instructions:

Write an analysis of the provided case that accomplishes the following:

1) State the significant issues of the case clearly and concisely, and explain why they are significant issues.

2) List the significant stakeholders and explain why each is a stakeholder.

3) Using appropriate business ethics theories and concepts, construct the best argument you can for the position on the case that you believe is correct. Be sure to explain the argument fully, demonstrate its impact on the significant stakeholders, and fully explain the theories and concepts you use to construct the argument. Note for those students who are familiar with the concept of standard form arguments: You may present your argument in standard form but you are not required to do so. If you do, be sure to explain your standard form argument in prose form.

4) Thoroughly explain the strongest objections that one might make against your argument.

5) Defend your argument by constructing the best responses you can to the objections you explained.

Selecting just the right case for each rendition of the exam is one of the most difficult tasks of administering the competency exam. On the one hand, we do not want to use a case that is too simple. A case with one single issue for which there is an obvious correct position has its merits in a classroom. Such a case can provide students with an entree into the discipline of business ethics that piques their interests and raises their confidence levels. Such a case, however, is not appropriate for a competency exam. The exam is not about piquing interests or raising confidence levels. It is about demonstrating competence. To do that, one must demonstrate the ability to work through more complex cases for which the correct positions are not obvious.

On the other hand, we do not want to use a case that is overly complex. A case that involves too many issues can cause students to become scattered and sketchy in their analyses. Students suffer from a very understandable fear that they will leave out some important point. Unfortunately, since they have a limited amount of time to write their analyses, they cannot cover every point that is pertinent to an overly complex case that involves too many issues.

Ideally, the case involves one or two significant business ethics issues with a variety of possible positions and arguments for those positions. We can then use the analyses to determine whether students possess the abilities to construct and critically evaluate arguments for various positions on business ethics issues. In particular, we can determine whether students can: 
1) identify the issue of a case,

2) identify the various plausible positions regarding the issue,

3 ) employ theories and concepts to construct arguments for the various plausible positions,

4) critically evaluate those arguments, and

5) construct and defend arguments of their own.

When we find that a student can do each of those things, we are confident that the student has demonstrated a competence to work through business ethics cases.

Sources of appropriate cases are abundant. Business ethics texts, casebooks, and journals are the most obvious sources, but newspapers and magazines are also excellent sources. ${ }^{2}$ In fact, although we have never used it, Meredith (1997) is a newspaper article that demonstrates what we look for in a case. The case deals with the practice of businesses reimbursing their sales staff for entertaining clients at strip clubs. Meredith explores the circumstances surrounding two lawsuits filed by women who lost their jobs from a company that engages in the practice. The women claim that they faced discrimination and harassment because of the practice. Although our purpose in the exam is not to test students' knowledge of the law, these lawsuits raise at least two important ethical issues that one who is competent in business ethics should be able to work through.

First, students should recognize that the case raises questions about discrimination. Although some women are comfortable in strip bars, it is not unreasonable for a woman to object to doing business in such environments. This is evident when one reads claims by salespersons such as this in Meredith (1997): "You get a bunch of guys together in a room who don't know each other, you get drunk and look at naked women and the next day you're great friends" (p. 1). A good analysis will examine whether the practice places women who do not wish to do business in strip bars in a disadvantaged position as they try to rise within the ranks of their companies. This worry is supported by a claim made by one of the plaintiffs. Meredith (1997) writes,

... her 'male co-workers were reimbursed in excess of $\$ 40,000$ annually for meals and entertainment of customers,' but that she was allotted a budget of $\$ 6,000$. And while the men spent thousands of dollars in strip bars, the company refused to reimburse her for $\$ 200$ she spent taking her customers to an ice-skating show ... (p. 25).

Students must recognize, however, that the case also raises questions about sexual harassment. Meredith (1997) writes of a brief by one plaintiff's attorney, "After heavy drinking . . . salesmen would "return to the workplace and sexually harass the female employees,," (p. 25). According to Meredith (1997), another attorney added that, by encouraging such entertainment, the companies involved ". . . 'aided, abetted, incited, coerced, and I'm saying compelled' the harassment" (p. 25). One should consider whether the practice is of the sort that leads to sexual harassment in the workplace and whether companies promote such harassment by encouraging their sales staff to entertain customers at strip bars.

Once students recognize these issues, they must demonstrate the ability to work through them by identifying the various positions one might take on these issues and by constructing and critically evaluating arguments for those positions. Although I cannot go into all of the possible positions and arguments that I would expect to find in analyses of this case, I will mention a few. With respect to the first issue, students should evaluate arguments for the position that the practice is discriminatory against women who object to doing business at strip bars because it 
places them in an unfairly disadvantaged position to obtain their firms' best clients and largest expense accounts. Moreover, students should evaluate arguments for the view that the practice is ethical because companies should be free to use their resources in whatever ways best enable them to obtain and maintain customers. With respect to the second issue, students should evaluate arguments for and against the view that companies are responsible for the sexual harassment perpetrated by those who return from entertaining customers at strip bars because the harassment is a foreseeable consequence of a practice condoned and promoted by those companies.

Meredith (1997), then, is a case with sufficient complexity to provide a true test of students' abilities. Moreover, it is simple enough so that it would not promote scattered and sketchy analyses. The issues that it raises are close enough that the case will not send students on searches for a wide variety of important points that they would be afraid to omit. Thus, the case would allow us achieve the goal of the case analysis section: to determine whether students possess the abilities to construct and critically evaluate arguments for various positions on business ethics issues.

\section{Results of the exam} briefly.

Developing and administering the exam has had two positive results that I will examine First, an analysis of the failure rate for the exam and its context provide good reason to believe that the exam is effective in achieving its overall purpose. Second, the impact that working on the exam has had on my teaching of the undergraduate business ethics course indicates that the exam has the potential to make business ethics courses better.

\section{Effectiveness}

We began our twice-annual offerings in 2001. Since that time, the failure rate has ranged from $20 \%$ to $30 \%$ and hovers around $25 \%$. In terms of effectiveness, this failure rate is significant for several reasons. First, students can take the exam only if they have completed an undergraduate business ethics course. The failure rate is not artificially increased by students who have not had a business ethics course. Second, students must pay a fee to take the exam. This fee covers the costs of developing and administering the exam, but it also serves as a deterrent to those who might want to take the exam even though they are unprepared. In almost all cases, the students who take the exam really believe they have done what is necessary to be competent in business ethics. The failure rate is not artificially increased by those students who simply want to give it a try and see what happens. Third, among those failures are some students who completed their undergraduate work at other schools as well as some students who completed their undergraduate work at my school. In fact, some of the failures were students who took my course. This means that the failure rate is not a function of students completing their ethics studies at other schools or with different professors at my school.

Although it is anecdotal, an encounter I had with one student is worth noting. This student had taken my business ethics course as an undergraduate. Unfortunately, he failed the competency exam when he entered the graduate program. Later, I ran into him in the hall and he told me he was on his way to the graduate Ethics and Business Environmental Issues course. My first thought was that he was bitter and was letting me know that, but he told me something 
interesting. He said that he came to understand how much he needed the course when he took the competency exam. The exam showed him that he needed to do more work in ethics. I hope that many of the students who fail the exam feel the same way and I hope the feeling is a product of the quality of the exam.

All things considered, I can safely say that the exam is not an easy hurdle to clear. Students must be properly prepared in business ethics to succeed. In this way, we have succeeded in maintaining our standards in the area of ethics.

\section{Effects on teaching}

Developing and administering the exam has had two related, positive effects on my teaching of the undergraduate business ethics course. First, developing the exam questions caused me to reflect on the goals I try to achieve in the course and how I try to achieve them. When determining the overall format of the exam and the types of questions it should contain, I had to give serious thought to the overall goals of the course. After all, a competency exam should determine who has and who has not achieved those goals. This reflection better organized my approach to the course the next time I taught it. I was able to articulate better the overall goals of the course to the students on the first day and I was able to review them better on the last day. Likewise, the actual construction of multiple choice questions made me give serious thought to my specific goals with respect to particular sections of material. Before I could construct questions on a particular section of material, I had to answer this question: What should a person who is competent in this material know? Answering that question for each section of material helped me to organize my classroom presentations better.

Second, the reflection spawned by the development of the exam has led me to make some concrete changes in the requirements of the course. Previously, I required students to address issues in business ethics by constructing arguments in valid, standard form. ${ }^{3}$ As a philosopher, I thought it important to require students to apply the rules of logic to their reasoning about the issues and to do so in the formal way that standard form arguments produce. After reflection, however, I dropped this requirement. Although constructing standard form arguments caused the students to developed an important skill, it did so in way that would not be useful to them in their careers as businesspersons. By working on the exam, I discovered that I could promote the skill I wished to promote better by requiring students to construct informal arguments rather than standard form arguments. After all, business managers are not called upon to make standard form arguments for one side or other of a business ethics issue but they are often called upon to make informal arguments.

Moreover, although I have always required students to write papers, I am currently experimenting with a new writing assignment that is the direct result of reflecting on what we expect students to accomplish when they write their case analyses for the exam. The assignment requires each student to write a research paper on a case that we do not cover in class. The student is responsible for finding the case in a newspaper or magazine and demonstrating that it is worthy of consideration. Then, the student must find at least one scholarly work that addresses the issue involved in the case. In the paper, the student must briefly explain the case, apply the scholarly work(s) to the case, and critically evaluate the results of that application. These requirements match very closely the previously- described five abilities that we associate with the case analysis in the exam. In a sense, developing and administering the exam has positively impacted my teaching in much the way that is sought by advocates of assessment of learning 
outcomes. It has caused me to reflect on the goals of my teaching and to make changes when appropriate based on that reflection. Since I do not teach the graduate course, I have limited my discussion to the undergraduate course. I have every reason to believe, however, that I would find the same positive impact if I taught the graduate course.

\section{Where do we go from here?}

As I stated at the outset, I hope this paper begins a discussion among business ethicists about both the merits of a competency exam and what the format of such an exam should be. I believe there are several questions we should pursue. These are the most important that come to my mind:

1) Are there drawbacks to the idea of a competency exam that we should take into account in the future?

2) What are the strengths and weaknesses of our current exam format?

3) Are there innovative ways to administer the exam that we could implement?

4) Are there areas of business ethics, issues, concepts, theories, or the like that must be covered on the exam?

5) What steps can one take to avoid "teaching to the exam"?

6) Is there any relationship between ethics competency and conduct?

7) Does ethics competency testing give a misleading impression regarding conduct?

8) Could the exam or something similar be designed so as to play a role in assessing learning outcomes?

9) Are there other possible purposes for the exam besides ours and that mentioned in $\# 8$ ?

10) Are there ways parties from various institutions could work together on such an exam?

11) Can organizations such as the Society for Business Ethics and the Association for Practical and Professional Ethics play roles in the possible collaboration mentioned in $\# 10$ ?

I hope others will consider these questions, and I look forward to their answers.

\footnotetext{
Notes

${ }^{1}$ My sincere gratitude goes to Dr. Jonathan E. Smith of John Carroll University's Boler School of Business for his partnership in that exam process.

${ }^{2}$ The following are just a few of the many cases that I believe would be appropriate for the exam: Carson (1998), Hasnas (1993), Jennings (1999), Lawrence (1993), Shaw (2002), Vandivier (1972), and Velasquez (1986).

${ }^{3}$ For those who are not familiar with standard form arguments, see Munson and Conway (2001).
}

\section{References}

Carson, T. L.: 1998, 'Ethical Issues in Sales: Two Case Studies', Journal of Business Ethics 17(7), 725728. 
Jennings, M. M.: 1999, 'Slotting, Facilitation, Costs or Bribery', in Business Ethics: Case Studies and Selected Readings, 3rd edn. (West Educational Publishing Company, Cincinnati), pp. 215-219.

John Carroll University: 2002-2004, Graduate School Bulletin.

Hasnas, J.: 1993, 'The Hazards of the Enterprise', in T. Donaldson and A. Gini (eds.), Case Studies in Business Ethics, 4th edn. (Prentice Hall, Upper Saddle River, NJ, 1996), pp. 141-143.

Lawrence, A. T.: 1993, 'Johnson Controls and Protective Exclusion from the Workplace', in J. R.

Boatright (ed.), Cases in Ethics and the Conduct of Business (Prentice Hall, Englewood Cliffs, NJ, 1995), pp. 148-159.

Meredith, R.: 1997, 'Male Bastion for Dealmaking Under Attack', The New York Times 1 (September 20), 25.

Munson, R. and D. A. Conway.: 2001, Basics of Reasoning (Wadsworth, Belmont, CA).

Shaw, W. H. 2002, 'Speaking Out About Malt', in Business Ethics, 4th edn. (Wadsworth, Belmont, CA), pp. 229-231.

Vandivier, K.: 1972, 'The Aircraft Brake Scandal', in T. Donaldson and P. H. Werhane (eds.), Ethical Issues in Business: A Philosophical Approach, 5th edn. (Prentice Hall, Upper Saddle River, NJ, 1996), pp. 345-356.

Velasquez, M. G.: 1986, 'Toy Wars', in Business Ethics: Concepts and Cases, 5th edn. (Prentice Hall, Upper Saddle River, NJ, 2002), pp. 379-383. 